\title{
RADICAL MORAL ENCROACHMENT: THE MORAL STAKES OF RACIST BELIEFS 1
}

\author{
Rima Basu \\ Claremont McKenna College
}

This is a penultimate draft. Please see the final version in Philosophical Issues.

\begin{abstract}
Historical patterns of discrimination seem to present us with conflicts between what morality requires and what we epistemically ought to believe. I will argue that these cases lend support to the following nagging suspicion: that the epistemic standards governing belief are not independent of moral considerations. We can resolve these seeming conflicts by adopting a framework wherein standards of evidence for our beliefs to count as justified can shift according to the moral stakes. On this account, believing a paradigmatically racist belief reflects a failure to not only attend to the epistemic risk of being wrong, but also a failure to attend to the distinctively moral risk of wronging others given what we believe.
\end{abstract}

\section{The Motivating Case}

A consequence of living in a society shaped by racist attitudes and institutions is that the epistemically rational agent-the one who attends to and believes on the basis of the strength of their evidence-may be forced to believe in accordance with evidence that supports beliefs that they would otherwise reflectively reject. For example, our social environment is one in which, to use a standard example from Tamar Gendler (2011), that the man standing in the lobby is black provides a substantial amount of evidential support for the belief that he is a staff member. On one hand, it seems that no matter how strongly race correlates with whether one is a staff member in your environment, it is morally impermissible to believe that he is a staff member. On the other hand, the belief seems epistemically justified. If one had more hands, one might go further and add that it would be epistemically irrational not to believe that he is a staff member as that would involve the willful disregarding of pertinent evidence. Many conclude that in such cases we face an irresolvable conflict between what morality requires and what we epistemically ought to believe. I disagree. I argue that we have the resources to resolve this tension if we take

\footnotetext{
${ }^{1}$ I am deeply grateful to the following people for comments on various drafts and interesting discussions that have helped shape my thinking on this topic (in alphabetical order): Mike Ashfield, Endre Begby, Steve Bero, Renée Bolinger, Gabe Dupre, Kenny Easwaran, Erik Encarnacion, Maegan Fairchild, Stephen Finlay, Jamie Fritz, Georgi Gardiner, Pamela Hieronymi, Jonathan Jenkins Ichikawa, Robin Jeshion, Gabbrielle Johnson, Shieva Kleinschmidt, Sarah Moss, Jessie Munton, Michael Pace, Mark Schroeder, Will Reckner, and Ralph Wedgwood. There are likely several people I've forgotten, and for that I sincerely apologize. I also apologize for any relevant literature that I've left out. The literature on moral encroachment has exploded in the time that this paper has been kicking around, and I am both relieved and terrified to finally let it go. Part of the fear involved in letting it go was not being able to respond to and incorporate everything that is being written. I also have to thank audiences at Duke, Wayne State, University of British Columbia, McMaster, Georgetown, Claremont McKenna College, Queen's, Simon Fraser, University of Missouri, University of Victoria, Virginia Tech, Barnard, the University of California Santa Cruz, and the Central European University. Your questions might not be addressed in this paper, but trust me, I'm still thinking about them.
} 
seriously the following nagging suspicion: the epistemic standards governing belief are not independent of moral considerations.

I will be developing an account of radical moral encroachment that is motivated by that very nagging suspicion. According to moral encroachment, the epistemic justification of our beliefs can be determined, in part, by the moral demands of our situation, i.e., the moral stakes. If we start with the intuitive thought that in some cases there are higher standards of evidence we must meet for our beliefs to count as justified-namely, high stakes cases-this framework lends itself naturally to capturing an additional way in which high stakes can be triggered-a failure to appreciate how you might morally wrong another person given what you believe. ${ }^{2}$

To begin making the case for moral encroachment, let alone a more radical form of moral encroachment, consider again the following standard case modified from Gendler (2011). In the following case, a social club's discriminatory membership practices have resulted in a stark racial divide between club members and staff members: only a small fraction of the club's members are black, whereas all of the club's staff members are black.

Social Club. Agnes and Esther are members of a swanky D.C. social club with a strict dress code of tuxedos for both male guests and staff members, and dresses for female guests and staff members. While preparing for their evening walk, the two women head toward the coat check to collect their coats. As they approach the coat check, they both look around for a staff member. As Agnes looks around she notices a well-dressed black man standing off to the side and tells Esther, "There's a staff member. We can give our coat check ticket to him."

In this case, it seems that Agnes's belief is justified. That the man standing in the lobby is black (together with the racial makeup of the club) provides substantial evidential support for the belief that he is a staff member. Agnes, however, has done something wrong. But what she's done wrong, on the face of it, doesn't seem like an epistemic mistake. Imagine, for example, that it's a busy night at the club with approximately 500 guests, only 5 of whom are black, and 50 staff members, all of whom are black. The chance of the welldressed black man being a club member is only $9 \%$, and the chance that he is a staff member is $91 \%$. Now in most cases, $91 \%$ certainty would be more than enough to justify believing. For example, if I told you there was a $90 \%$ chance of rain tomorrow, it wouldn't be irrational to believe that it'll rain tomorrow. Further, if I asked you what you were planning to do tomorrow and you said you were planning to throw a BBQ, that'd be really odd. You'd be epistemically criticizable for disregarding the evidence. ${ }^{3}$ If we are justified in

2 See Basu (Forthcoming, 2019) and Basu and Schroeder 2019. For other defenses, see Fritz (2018), Pace (2011), Schroeder (2018), Bolinger (Forthcoming), and Moss (2018a, 2018b). I also borrow the terminology of radical moral encroachment from Jamie Fritz, who first marks a distinction between moderate and radical forms of moral encroachment in his paper, "Moral Encroachment and Reasons of the Wrong Kind" (in preparation). See also Alex Worsnip's (Forthcoming) distinction between hard and moderate pragmatists and how to understand varieties of moral encroachment within that framework.

3 There is something problematic about the agent who would never believe that it'll rain tomorrow short of certainty. Nonetheless, you might feel that the $90 \%$ chance of rain is not sufficient to be justified in believing that it'll rain tomorrow. In such a case, we can change the case however we need to meet whatever higher threshold you desire for the agent to be justified in believing that it'll rain tomorrow. Notice further that although we can do this kind of evidential tinkering with the rain case until you have sufficient certainty to believe, the race case is different. There is more moral resistance no matter how high the threshold is, and this suggests that there is something in principle problematic about believing on the basis of problematic social trends that can't be washed out by tinkering with the evidential support. This moral resistance is what I hope to capture in my account of moral stakes. The moral resistance we feel is this risk of wronging, not merely the risk of being wrong. The latter is all that's at work in deciding where to place the threshold for rain beliefs. 
believing that it'll rain tomorrow on the basis of a 90\% chance of rain, wouldn't Agnes be similarly justified (or more justified) in believing that the well-dressed black man is a staff member?

Despite seeming epistemically justified, believing a person is staff on the basis of their skin color is a paradigmatic case of racism. Thus, such a case, and others like it, raise the troubling possibility that by simply attending to our epistemic obligations, we may contribute to the harms and wrongs of racism. In particular, we contribute to the harms and wrongs that accompany being racially profiled. ${ }^{4}$ In light of such cases, one might be tempted to follow Gendler and conclude that we face an irresolvable conflict between our moral obligations and what we epistemically ought to believe. I disagree. I suggest that these cases push us to rethink the assumption that pits moral considerations and epistemic considerations against each other: namely, the evidentialist assumption that the only considerations relevant to whether you should believe are evidential considerations. According to a standard presentation of the evidentialist position, moral considerations are neither here nor there when it comes to the question of whether a belief is justified. This assumption will be my target.

\section{TARgETING EVIDENTIALISM AND ROUTES TO MORAL ENCROACHMENT}

Evidentialism is committed to the claim that a doxastic attitude $p$ is epistemically justified if and only if that doxastic attitude fits with the evidence you have for $p$ (see Conee and Feldman 2004). To get the intuitive feel for evidentialism, consider the following case. Suppose your friend Veronica tells you that she believes that the moon landing was a hoax. Not wanting to dismiss her out of hand, you go on to ask her for what evidence she has. Veronica offers you some evidence that suggests that the moon landing was filmed on a sound stage. For example, the surprisingly high quality of the footage and the lack of stars in any of the photographs. We recognize that Veronica is mistaken. But, we also recognize why she believes what she does: she has some evidential basis for her belief. In a sense Veronica's doxastic attitude "fits with" the evidence she has for her belief that the moon landing was a hoax, but the evidence clearly doesn't justify the attitude. The reason we find her to be mistaken is that she does not have a sufficient evidential basis for her belief. Given that her evidence can be easily debunked she not only needs stronger evidence, she also needs more of it.

This vignette illustrates that the relationship between evidence and justification is not straightforward. This point complicates the standard evidentialist picture since,

\footnotetext{
4 I've argued extensively in other work for the claim that this is in fact a racist belief and, ipso facto, morally problematic. I want to avoid rehashing all of those arguments here and take this point for granted. However, I will quickly address one common refrain that accepts the morally problematic nature of the case but suggest it's not the belief that's morally problematic but the action on the basis of the belief. That is, you might worry here that in such cases the issue concerns treating someone as staff rather than believing that they are staff. To address this worry would take too long in this paper, and I give a longer treatment of this objection in Basu (Forthcoming). For the purposes of this paper, I will just make the following suggestive remark for why I disagree: in such a case, even the mere thought that someone is a staff member given their race-absent any overt action-is still insulting (though maybe not as insulting). As an analogous case, imagine a person informing you that they believe women are bad drivers. Noticing your grimace, they assure you that despite this, they would never actually treat a woman any differently. Here, even if they're correct that they could avoid having these beliefs affect their actions (a claim that itself is dubious at best), that does not make the belief any less insulting. See also Basu (2019) and Basu and Schroeder (2019) for more in defense of the claim that the belief itself can wrong.
} 
although the evidentialist is correct to note that there is a connection between justification and evidence and that we should believe in accordance with the evidence, this gloss is too simplistic. Evidentialism, in its minimal and most intuitive form, leaves open two distinct questions about what it means for a doxastic attitude to "fit with" your evidence. Whether a belief is epistemically justified depends on not only what our evidence is but also whether the evidence is sufficient. ${ }^{5}$

We can articulate this minimal intuitive gloss on evidentialism in the following probabilistic way: for each proposition $\mathrm{p}$ and body of evidence $\mathrm{E}$, there's some threshold for justification, call it $t$, that it's permissible to believe $\mathrm{p}$ on the basis of $\mathrm{E}$ only if the probability of $\mathrm{p}$ given $\mathrm{E}$ is greater than or equal to $\mathrm{t}$. That is, the probability of $p$ given $E$ is a probabilistic gloss on the notion of strength of evidence for the proposition under consideration, and $t$ simply corresponds to a sufficiency condition that the strength of one's evidence must either meet or surpass to be justified. Call this idea Support.

For example, consider whether you are justified in believing that the kettle has boiled. The sound of a kettle whistling raises the probability of the belief being true. Further, it raises the probability higher than if you had just glanced at your watch and seen that the kettle has been on for two minutes. Both make it more likely than not that the kettle has boiled, but only the sound of the whistling raises the probability to a degree that is sufficient for being justified in believing that the kettle has boiled.

However, that threshold need not be the same for every belief. In some circumstances you would want stronger evidence, i.e., would want the threshold to be higher. In others, you might require weaker evidence, i.e., for the threshold to be lower. For example, when adjudicating someone's guilt in a criminal case, the threshold is higher than when adjudicating a playground dispute. All of this is consistent with there being some threshold that the strength of one's evidence must cross in order to justify belief. Justification, then, is more than merely what evidence one has.

We now start to see where stakes-based encroachment accounts in epistemology gain traction: non-evidential considerations plausibly play a role in settling the question of how much evidence is enough evidence. Suppose you are not allergic to nuts but simply have a general dislike for them. In such a case, a waiter's assurance that they're "pretty sure" there aren't nuts in any of the dishes would be sufficient for you to justifiably believe that there aren't nuts. However, if your dining partner Sarai is deathly allergic to nuts, then the waiter's assurance no longer suffices. Sarai, given the stakes, should not believe that none of the dishes contain nuts. However, the evidential situation for both you and Sarai is identical. Proponents of stakes-based encroachment views in epistemology argue that the difference in our intuitive judgements concerning justification suggests that justification depends not only on the evidence, but also what's at stake and by changing a practical feature of the scenario-what is at stake for Sarai-we have thereby changed what she is epistemically justified in believing.

Such a view, however, is controversial (see, for example, Brown 2013). Despite the controversy, many have begun to argue that moral features can also make such a difference to justification and epistemic rationality. For example, Michael Pace (2011) suggests that there is no purely epistemic rationale for setting the threshold for

\footnotetext{
${ }^{5}$ One might worry here that evidentialism doesn't have any intuitive plausibility to start with. Consider, for example, that evidentialism fails as an explanation for the justificatory status of certain classes of belief. Reasons to believe mathematical truths or a priori truths do not rest on one's evidence, nor do cases of selfknowledge require that an agent believe in accordance with her evidence. However, for empirical beliefs, like Veronica's, evidence does seem like what we look for to determine whether the belief is rational and justified. Since beliefs about others are empirical, evidentialism seems an apt requirement on such beliefs.
} 
justification in one place rather than another. Rather, the evidential standards one adopts, i.e., how one determines the threshold, is determined by and varies according to both pragmatic and moral factors. Similarly, although Sarah Paul and Jennifer Morton (2018a, 2018 b) do not call their account an account of moral encroachment, they do note that, although evidential policies govern the way we adjust our evidential thresholds in different contexts, there is no uniquely best evidential policy to have. There are multiple evidential policies that are rationally permissible for a given thinker to have from the point of view of purely epistemic considerations. Further, if that's the case, then practical and ethical considerations can and should play a role in deciding between epistemically permissible policies. $^{6}$

Further, in an account of moral encroachment that is offered by Sarah Moss (2018a, 2018b) and Renée Bolinger (2018), when we use statistical reasoning about a group to conclude something about an individual member of that group our failure to keep in mind the salient possibility that the individual may be an exception to the statistical generalization is both a moral and an epistemic failing. However, given that Bolinger and Moss's account concerns beliefs formed on the basis of statistical generalizations, we might worry that there is something objectionable about the statistical nature of the evidence on which the belief in question is based. One might argue that what makes the moral stakes high is itself the statistical nature of the evidence, e.g., such beliefs would fail standard criteria for knowledge such as safety or sensitivity. ${ }^{7}$ Although this is another way to present an account of moral encroachment, if we go this route, we face two questions. First, the question of why statistical generalizations are uniquely subject to moral considerations, whereas forming beliefs on other kinds of evidence isn't. ${ }^{8}$ Second, we also face the question of why some beliefs formed on the basis of statistical evidence seem fine whereas others don't, i.e., as the question has been put by Frederick Schauer (2006): what's

\footnotetext{
${ }^{6}$ These points, however, are not new. Although the connection is not often drawn, these points are echoed in feminist critiques of the value-free ideal in science. For example, Richard Rudner (1953, p. 2) makes the point that "our decision regarding the evidence and respecting how strong is "strong enough", is going to be a function of the importance, in the typically ethical sense, of making a mistake in accepting or rejecting the hypothesis." See also Rebecca Kukla (2015) who notes how the discussion of the interest-relativity of evidence has occurred in isolation from the literature on inductive risk. See also Heather Douglas (2009) and Helen Longino (1987) for more on feminist critiques of the value-free ideal in science. Further, prior to pragmatic encroachment, Lorraine Code's (1987) account of epistemic responsibilism seems to gesture at a similar point. ${ }^{7}$ See, for example, Munton (2019) and Gardiner (2018) for critiques of this kind.

8 Within legal scholarship this is known as the problem of naked statistical evidence. See, for example, Schauer (2006) and Buchak (2014). The common example goes as follows: we know that a bus has hit an individual, but the individual cannot identify the bus. $80 \%$ of the buses in the city are blue buses operated by the Blue Bus Company, whereas the other $20 \%$ are red and operated by the Red Bus Company. Given the balance of the probabilities, the individual was probably hit by a blue bus. However, this merely statistical evidence is not permissible in the courtroom. Further, if we had an eyewitness who was only reliable $80 \%$ of the time, that testimony would be allowed. Thus, we face a problem of explaining why the testimony is allowed, but the statistical evidence is not allowed. I set aside the issues as they appear in the legal scholarship, as my focus is not whether there is something objectionable about beliefs formed on the basis of statistical evidence. Rather, as I've stated, my focus is on beliefs that are formed without attention to the moral demands of one's environment
} 
the contrast between profiling pitbulls on the basis of statistical evidence as opposed to people? ${ }^{9}$

A strength of the radical moral encroachment picture that will be defended in the next section is that it can answer these two questions. A central claim of radical moral encroachment is that certain beliefs have high moral stakes because such beliefs risk wronging, not only being wrong. We do not wrong objects when we form beliefs about them, but we do wrong agents. The primary examples motivating radical moral encroachment concern evidential environments that have been shaped by racial discrimination and racial stereotypes and how the beliefs we form contribute to the epistemic-structure of the social environments we navigate.

Finally, another route that has been offered to moral encroachment is noting that insofar as there are good arguments for pragmatic encroachment, there are analogous good arguments for moral encroachment (see Fritz 2018). However, there are two issues we'd have to confront if we go this route. First, the examples often used are direct analogues to the traditional pragmatic encroachment cases and to rest a defense of moral encroachment on the plausibility of any particular account of pragmatic encroachment risks the plausibility of moral encroachment being undercut by less plausible versions of pragmatic encroachment. For example, such accounts tend to be motivated by a connection between knowledge and action (or justification and action). ${ }^{10}$ These stakesrelated reasons, arise from the risk of error. Whereas traditional accounts of pragmatic encroachment have focused on practical costs, I suggest that a distinctive feature of moral encroachment is that moral risks of error are a special case of risks that aren't tied directly to action. Rather, the risks are incurred simply by believing. ${ }^{11}$

${ }^{9}$ I suspect the degree to which we feel uncomfortable with the pitbull induction will vary with respect to the degree to which we see them as agents that are themselves a part of our social environment. As much as I love my dog, dogs are not people. We shouldn't have the same intuitions in the two cases and although the inference that pitbulls are dangerous is intimately connected to the racial disparities I am interested in - the motivation behind breed specific legislation may not really be about the dogs at all but rather be a matter of a proxy by which some groups can target others on the basis of suspicions they have related to class, race, and ethnicity (see Dickey 2017) - it would obviously be insensitive and naïve to put this mistreatment at the same level of the racial oppression of human agents.

10 For example, Stanley (2005) argues that his version of pragmatic encroachment, interest-relative invariantism, is motivated from an intuitive connection between knowledge action. Similarly, Fantl and McGrath $(2002,2009)$ build their account of pragmatic encroachment around the following principle linking knowledge-level justification and action: If you know that $p$, then $p$ is warranted enough to justify you in $\varphi$ ing, for any $\varphi$. In these standard accounts of pragmatic encroachment practical considerations encroach because of an intuitive connection between knowledge and/or justification and action. The case that I have been using to motivate moral encroachment, however, does not concern action. The case concerns our beliefs about others. This raises worries about whether this will be a straightforward application of pragmatic encroachment, and these are worries that I am sensitive to. Moral stakes, we will see in Section 3, encroach in a manner dissimilar to practical stakes. Nonetheless, this remains a stakes-based encroachment account.

11 To add one more account of moral encroachment, Mark Schroeder and I have previously defended another account of moral encroachment as a response to what we called the problem of coordination (see Basu and Schroeder 2019). That is, moral encroachment offers a promising answer to resolving the following sort of tension: how can a belief be rational in every way required for knowledge but still be morally wrong? If moral encroachment is right, then that troubling question does not arise. After all, if moral encroachment is right then it's not possible for a belief to be rational in every way required for knowledge while still being morally wrong. The motivation for radical moral encroachment I will offer in this paper, however, presents another route to moral encroachment. In this paper my goal is to show that the construal of epistemic rationality as believe in accordance with the evidence is fully compatible with epistemic rationality being sensitive to practical and moral considerations. In short, my strategy in this paper is to show that the moral isn't really encroaching in epistemology, it has been there all along. For one more alternative route to moral encroachment, see also Schroeder (2018) 
To motivate radical moral encroachment, we must bring together two threads that have been running through this paper. First, an unfortunate feature of our world, to put it lightly, is that our epistemic environments are often shaped by racist institutions and practices. The social club described in Section 1 is not an anomaly. There are many spaces we move through which have had histories of exclusion. As a result, when it comes to forming beliefs about who belongs in that space or doesn't, who is a staff member and who isn't, these beliefs are high stakes beliefs. Further, these stakes aren't practical stakes. They are moral stakes. The practical cost of missing a mortgage payment or getting on a slower train (as in traditional cases of pragmatic encroachment) is very different from the kind of moral stakes involved with racist beliefs. The moral stakes concern other people and their standing in the world, their dignity, and respect. Consider again why being mistaken for a staff member is a paradigmatic example of racism. Underrepresented groups are more often mistaken for employees because of the color of their skin and the racist institutions that make their skin color such a determining factor of their inability to gain access to more prestigious employment opportunities. Being mistaken in this context, namely one in which you've historically been excluded, is a moral wrong that is absent in spaces where that historical disadvantage is lacking. The evidentiary standard Agnes must meet before she can justifiably believe that John Hope Franklin is a staff member is higher given the moral risks involved. Just as practical stakes can make it harder to believe, be justified, or know, so too can the moral stakes.

Next, there are two upshots to bifurcating the question of what we should believe into practical and moral considerations. First, we have opened a space for moral considerations to be part of the answer in a non-ad hoc way. Second, we preserve the minimal version of the evidentialist assumption that is responsible for generating the moral-epistemic conflict in the first place. Agnes, recall, fails both epistemically and morally. Given the higher moral stakes her evidence does not pass the higher evidentiary burden she must meet. In ignoring the moral demands of her environment, i.e., the moral wrong that would be done forming her belief about a black man in a space where he has been historically excluded, Agnes fails to see that she lacks sufficient evidence to believe. Thus, her belief is both morally objectionable and epistemically irrational and we can capture the intuitive sense in which racist beliefs, and beliefs that seem like they could wrong, require more justification than other beliefs.

\section{Why RADiCAL MORAL ENCROACHMENT ISN'T PRAgMATIC ENCROACHMENT}

My strategy now for demonstrating why radical moral encroachment isn't just a straightforward extension of pragmatic encroachment is to show that if it were, we would expect certain analogous cases to hold but they do not. First, pragmatic encroachment is motivated by contrasting pairs of cases, one LOW and one HIGH. These cases are created by simply toggling a practical feature in the low stakes case to make it high stakes while leaving the evidence the agent has in the case unaltered. The change in our intuitions regarding justification or knowledge in the high stakes case then demonstrates that our intuitions about justification or knowledge are sensitive to the change in practical stakes. Intuitions about justification in cases involving moral stakes, however, not toggled in the same way. We cannot create minimally contrasting low stakes variants of morally high stakes cases. Second, if moral encroachment is a straightforward extension of pragmatic encroachment, then moral stakes should be a straightforward extension of practical 
stakes. However, in conjunction with my first argument, I argue that, whatever moral stakes are, they must be understood differently than practical stakes.

Let us start by considering Social Club again. Plausibly, Social Club is a high stakes case. To build a contrasting case, then, we must ask three questions. First, what would the low stakes variants of the traditional pragmatic cases be; second, what is it that makes these cases high stakes; and third, is what makes these cases high stakes the same in both the pragmatic and the moral domains. To answer the first question, we need a low stakes case in which an agent is permitted to believe $p$ and a high stakes case where the agent is not permitted to believe $p$. These questions are related: understanding the source of difficulty in building minimally contrasting low stakes variants for moral considerations will in turn help us answer the second and third questions.

Consider the following attempt to construct a low stakes case and a contrasting high stakes case for Social Club.

The Enlightened Northerner. Nathaniel is an enlightened visitor from the North who likes to keep track of how well-staffed social clubs are. He has found that in the South, staff are predominantly black. During his visit to the Cosmos Club, he mentally makes a note of each black person he sees as a staff member, and at the end of day, he leaves for the rest of his journey with the belief that there was one staff member for every ten guests. One of those people he counts as a staff member is John Hope Franklin, the club's first black club member.

The Racist Club Member. Duke is a racist member of the Cosmos Club. Service has been bad today, so he wants to reprimand a staff member in front of a lot of people in order to call attention to his dissatisfaction with the service. Furthermore, he wants the race of the staff member to be a major focal point of his complaint. Duke sees a well-dressed black man standing off to the side, and, being a racist, assumes on the basis of his race that the staff member must be lazy and deserving of punishment. Duke then proceeds to confront the man in an attempt to make an example of him. ${ }^{12}$

One might think that only one of these cases demonstrates a wrong. According to this line of thought, Nathaniel doesn't commit a wrong, but Duke clearly does. But I disagree. Nathaniel also wrongs John Hope Franklin when he so easily believes that he is a staff member. Nathaniel is ignoring how his environment is shaped by the South's racism, which here serves as the relevant moral feature of his environment that he is insensitive to. Consider further how we would feel if Nathaniel did take this into account. That is, given how racist the South is and the severe degree to which black men are prevented from occupying roles that would put them on equal footing with the club members, Nathaniel reasons that he's in a very good evidential position to form his belief that John Hope Franklin is a staff member. I can grant this and still note that this lends further support for considering moral encroachment as something distinct from pragmatic encroachment. From a practical considerations point of view Nathaniel has more reason to believe, but from the moral considerations point of view he is doing something wrong. It is for this reason that both Duke and Nathaniel fail to be justified in their beliefs. Moreover, these same considerations lead me to believe that both Duke and Nathaniel would fail to be

12 This set of cases was first suggested to me by Steve Bero. 
justified even if the person they picked out is in fact a staff member. ${ }^{13}$ Both fail to show the moral care demanded by the unjust nature of the environment they find themselves in.

There's an oft-cited slogan that facts can't be racist. Perhaps a good way of summarizing the crucial points of radical moral encroachment is with the following. Facts may not be racist, but they may be products of racism. When reasoning about these facts, we must not ignore their provenance. Thus, when forming beliefs on the basis of evidence that is a result of our racist history, it seems appropriate to ask for more moral care. But what, precisely, does this moral care amount to? It cannot simply be recognizing that the environment is racist. That doesn't seem to be enough-for example, you might think that Nathaniel can recognize that fact, but then use that very fact as evidence that the black person he is seeing in the club is a staff member. So, being sensitive to it isn't merely a matter of knowing that we're in a racist environment. Moral sensitivity amounts to not only a recognition of an unjust environment, but also an adjustment of one's threshold for justification to meet the moral stakes of that environment. Because what exactly moral sensitivity amounts to turns on the deeper question of what being a moral person requires of us, giving a full account of sensitivity will require a much deeper analysis than available here. But it's a start.

To illustrate with another analogy, consider the following case. You study AfricanAmerican history and you are putting together a book on poverty in 1930s America. Your focus is specifically on poverty in black communities, so you are visiting archives and collecting photos. The 1930s were a difficult time, and you have very good reason to think that almost any picture you come across of an African-American family will be a picture of a family living in poverty. However, one of the pictures you include is of an AfricanAmerican family not living in poverty. Contrast this case with one in which you are a photographer putting together a book on North Dakota ranches and one of the pictures included in the book is mistakenly a picture of a South Dakota ranch. There is a wrong in the former case that is different from the latter. It is not merely a matter of presenting things accurately. The problem in the first case is that there exists a neglected demand for extra care and diligence when believing things of others. This same demand is not present when believing things of ranches. I suggest that what is going to separate a high stakes case from a low stakes one is that the wrong that's being done has to do with the added layer of a moral injustice and concerns our interactions with other moral agents-in this case taking the form of a racial injustice.

Let's return to our three questions. Regarding the first-what would the low stakes variants of the traditional pragmatic cases be-we see the source of difficulty for creating minimal contrasting low stakes cases for moral encroachment is due to the very features that makes these high stakes cases. This, in turn, leads us to an answer to the second question-what is it that makes these cases high stakes? Answer: the socio-historical context in which the features are formed. Underrepresented groups are more often mistaken for employees because of the color of their skin and the racist institutions that make their skin color a determining factor in their inability to gain access to more prestigious employment opportunities. Being mistaken in this context, namely one in which you've historically been excluded, is a greater harm and wrong than being mistaken in a space where that historical disadvantage is lacking. It is this social and moral fact that we've been neglecting. It is this social and moral fact that makes all the cases so far seem

\footnotetext{
13 This is a difference between Schroeder (2018) and me. On Schroeder's view, only false beliefs can wrong someone. However, the moral wrong involved in the kind of racial profiling that John Hope Franklin experiences, and the waitstaff in The Enlightened Northerner experience, does not depend on whether the profiling is true or accurate.
} 
like high stakes cases. I conjecture that this is because of how deeply our social environments are steeped in and shaped by a history of racism. So, whereas we can toggle high stakes for agents in traditional pragmatic encroachment cases by stipulating that they have mortgage payments due, we cannot simply toggle a history of racism on or off to make simple high/low pairs of cases.

To envision such an environment for a low stakes variant would require invoking something like a twin-earth type scenario where our society hasn't been shaped by the racist events and practices that it has. To do this we have to imagine a world where racism hasn't formed the bedrock for society. What would that world be like? Presumably it would be one where a person's skin color is as relevant to one's social status as say, the length of one's index finger, is in the actual world. Whatever that world is like, it has to be very different from our actual world, incommensurably different even. To imagine such a scenario is to so widen the distance between this world and the actual world that the comparison would ultimately have no substantive relevance, thus failing to constitute anything like a "minimal pair." Potentially we could still try to build a minimal pair of cases by contrasting cases in which we reason about a dominantly-situated agent in the low stakes case and a non-dominantly situated agent in the high stakes case. Note, however, that this still won't fulfill the same structure as the minimal pair cases motivating pragmatic encroachment because we are changing the people involved in the cases. To have the minimal pair we need two cases that are identical in every way except that in LOW there are no moral stakes and in HIGH there are moral stakes.

One might still wonder whether these moral stakes are simply practical stakes. If so, it might seem that moral encroachment is a mere extension of pragmatic encroachment, rather than a view that brings with it anything novel, surprising, or distinctive. This brings us to the third question that I set out at the start of this section: is what makes these cases high stakes the same in both the pragmatic and the moral domains? Ultimately, I will reject the idea that moral encroachment is a mere extension of pragmatic encroachment. However, for now, it will be helpful to explore this possibility. One way to conceive of moral encroachment as a version of pragmatic encroachment is to consider it an extension of practical stakes to others rather than ourselves. For example, consider the following first-pass distinctions.

Practical Stakes. A risk of being wrong you impose on yourself when you believe on the basis of insufficient evidence.

Moral Stakes (First Pass). A risk of being wrong you impose on others when you believe on the basis of insufficient evidence.

Practical stakes concern the agent's preferences, whereas moral stakes take into account other people's preferences. This is a point that has already been recognized. For example, consider the following pair of cases from Ross and Schroeder (2012, p. 261):

Almond Butter-Low. Five minutes ago, Hannah made three sandwiches and placed them in the refrigerator. She told Sarah that she placed the peanut butter sandwich on the left, the tuna sandwich in the middle, and the almond butter sandwich on the right. Hannah then departed just as Sarah's friend Almira arrived for lunch. Sarah knows that Almira has no allergies. Almira says: "I'd love an almond butter sandwich." And so Sarah opens the refrigerator door, points to the sandwich on the right, and says: "The sandwich on the right is an almond butter sandwich. You can have it."

Almond Butter-High. This case is just like Low, except here it is Sarah's nephew Algernon who is visiting for lunch, and he has a severe peanut allergy. He asks 
Sarah for a sandwich. Sarah knows that the peanut butter sandwich would be fatal to Algernon, but that the almond butter sandwich would be harmless. She also knows that he would slightly prefer the almond butter sandwich to the tuna sandwich. When Sarah goes to the fridge, she can tell by visual inspection which is the tuna sandwich, but she cannot tell by visual inspection which is the peanut butter sandwich and which is the almond butter sandwich. So she gives him the tuna sandwich.

These cases illustrate that it is not only your own stakes that can change whether you are justified in believing p, but also whether someone else is in a high stakes situation with regard to $\mathrm{p}$ can change your justification as well.

In both cases, Sarah has the same evidence and the evidence supports the proposition that The sandwich on the right is an almond butter sandwich to the same degree. However, given the risk involved with acting on that belief for Algernon, our intuitive response is that Sarah is not justified in believing that the sandwich on the right is an almond butter sandwich. So, despite being in the same evidential situation, Sarah is justified in Almond Butter-Low and not justified in Almond Butter-High. As a result, it appears that not only do the stakes for the believer make a difference to whether she is justified, but the stakes for those who would be affected by her acting on the belief make a difference to whether she is justified. But if this is all that moral stakes are, this is uninteresting.

Instead, as I have been suggesting, what is morally at stake in the cases we began with is an added insensitivity to background features of one's environment. This involves a broadening of our understanding of how our epistemic practices are environmentsensitive. There is a morally and epistemically problematic form of insensitivity that I have outlined earlier. This sensitivity is distinctive to our moral agency and it is what separates cases of high practical stakes concerning other people from high moral stakes concerning others. Thus, it's critical that we capture this potential for insensitivity in our gloss of moral stakes. Here's a second-pass attempt to capture this point:

Moral Stakes (Second Pass). The risk one imposes on another person by failing to respond with sufficient sensitivity to the morally relevant features of the environment when settling a belief.

This gloss on moral stakes focuses attention on what the non-evidential features relevant to settling belief in these cases are. Namely, the relevant features are moral facts that you should be sensitive to. This gloss captures something ignored in our usual way of thinking about what the stakes are, and fits the following way to understand moral encroachment: as the demand to be woke. To be woke is to be aware of the moral demands of one's environment. With regard to our epistemic practices, it is the demand to be aware of the moral stakes of our beliefs about one another. It is the demand to be aware of the background against which our epistemic practices exist, i.e., the unjust world we inhabit, and to ensure that our epistemic practices are not only responsive to unjust features of our environment but that they also do not themselves contribute to those unjust features of our environment. In short, it is a demand to practice what we might call good epistemic housekeeping going forward. ${ }^{14}$

Although this bears some similarity to the idea of practical stakes, it cannot be subsumed under our understanding of practical stakes. Recognizing that our environment

14 Thanks to Lisa Miracchi for pressing me to say more about this. The idea remains underdeveloped, but I think its value-even as an initial attempt to name a kind of epistemic virtue we should be trying to habituate within ourselves-is significant. 
can place moral demands on our epistemic practices results in a more robust form of pragmatism than is commonly defended. As a result, we should not think of radical moral encroachment as merely a straightforward application of pragmatic encroachment; rather, it builds upon the foundations laid by pragmatic encroachment and extends our understanding of the non-evidential considerations that matter for justification. ${ }^{15}$

\section{SOME WORRIES}

To wrap things up, here are three seemingly perverse consequences that this account of moral encroachment might have. First, consider people who grow up in deeply prejudiced social settings with no access to contrary evidence. As Endre Begby (2018) argues, these people should be counted as victims. If you had the bad luck of growing up in a severely constrained socio-epistemic environment, then holding you responsible and morally blameworthy for the predictable consequences of your limited epistemic opportunities would be perverse. It would compound your plight.

Second, consider what this account of moral encroachment would recommend when it comes to believing things of any member of non-dominantly situated group. You must walk on epistemic eggshells. ${ }^{16}$ However, by only walking on epistemic eggshells around members of non-dominantly situated groups and being more free in your epistemic practices around members of dominantly situated groups you may end up compounding a wrong that's done to them. Relatedly, whereas I have focussed on cases in which we wrong by believing when our evidence doesn't meet the higher evidential threshold demanded by the moral stakes, when it comes to members of non-dominantly situated groups it seems we also wrong them when we refrain from believing or when we fail to believe.

To address the second challenge first let us consider the example of failing to believe on the basis of a woman's testimony that she has been sexually harassed or assaulted. It would be inappropriate to say that it's a case in which the stakes are high and so the

\footnotetext{
15 There is a point to be made here about how the cases that are traditionally used to motivate pragmatic encroachment rely on A-stakes (see Worsnip 2015). A-stakes track what is at stake with respect to whether an agent believes (or relies) on the proposition. On the other hand, there are W-stakes which track what is at stake respect to whether the proposition is true or false. That is, the relevant cost is the cost of the proposition of the potential belief being true versus being false as opposed to the cost of relying on the belief should it be false. Worsnip presents the following challenge for accounts of stakes-based encroachment: only a W-stakes reading preserves intuitions about knowledge attributes, whereas only an A-stakes reading preserve the putative link between knowledge and practical reasoning that motivates many pragmatic encroachment accounts. But as we see in light of the cases of interest to this paper, not only does it seem that our intuitions about knowledge-attributions differ according to W-Stakes and A-stakes, but perhaps there are also M-stakes that don't quite operate in the same way as either W-stakes or A-stakes.

As noted above, $\mathrm{W}$-stakes are the stakes as to whether the proposition is true, whereas A-stakes are the stakes as to whether the subject ought reliantly believe or withhold from believing p. M-stakes are neither quite W-stakes or A-stakes. After all, in Social Club, it doesn't make sense to say that the W-stakes are high or low. Partly why this is difficult is because Worsnip only presents A-stakes and W-stakes as they pertain to you, not to others. For example, you might think that we perhaps could capture the stakes for others in terms of the W-stakes. But, Worsnip's W-stakes only consider how the world turning out a certain way rather than another would be bad for the believer. Hence, it is unclear to me what the mapping between A-stakes, W-stakes, and moral stakes would be. A conclusion we can draw, however, is that the matter of stakes and what kind of stakes there are, or more difficult than initially thought. There are not only plausibly two kinds of stakes, but potentially three. Thanks to Jessie Munton for pressing me on this point.

${ }^{16}$ I cannot remember who first asked me this question or suggested this phrase. I feel like it was either Amy Kind, Adrienne Martin, or Michele Moody-Adams. I'm sorry for forgetting who it was as this is a challenge that keeps me up at night.
} 
threshold for settling belief is also higher. What this suggests, however, is two important points. First, we have more evidence for the claim that practical and moral stakes differ. Precisely the harm done by judges who suggest leniency in sentencing because of the risk to the rapists future is that the judges are focussing on the practical stakes, not the moral stakes. This brings us to the second point that what's morally at stake in these cases is this background history of discrimination and discounting of the testimony of assault victims. This further suggests that the moral stakes can not only raise the threshold for evidence, but also lower it.

I am skeptical, however, that we'll be able to articulate a general principle to determine in every case whether the threshold goes up or whether the threshold ought go down. The very same class of evidence-fact patterns that are the basis or result of an injustice - and the very same way of relating to others-taking the moral standpoint-can sometimes make the threshold go up and sometimes down. For example, it is easier (and perhaps ought be easier) to believe well of our friends. The threshold is lower. Similarly, perhaps to address the epistemic eggshells concern, when it comes to some situations we should be more ready to believe things of vulnerable groups than otherwise. Although I offer this as a possible answer, I myself remain wary, and I find myself wanting to bite the bullet when it comes to the epistemic eggshell worry. More is demanded of us in our interactions with and beliefs pertaining to non-dominantly situated groups. Often correcting for injustices involves adopting practices that appear unfair, but in reality are serving as a counterbalance for a history of unfairness. Perhaps there is no way we can completely morally relate to one another as we would in an ideal world, but that is just a reflection of the non-ideal world we find ourselves. ${ }^{17}$

To return to the first version of the perverse consequences worry, let me start by noting that although this is a serious challenge I think it brings to light a promising feature of taking the idea that moral stakes track what it means to do right by someone when it comes to what we believe of them. To see this, let me start with a biographic note. I did not learn about residential schools until I attended university. In no history textbook, class, or conversation was the fact that First Nation, Inuit and Métis children were removed from their homes and communities in the name of "assimilation" ever taught to me. What I was taught-what all Canadian children were taught-was constrained by a socio-epistemic environment that deeply wrongs First Nation, Inuit and Métis peoples. As I make revisions to this paper, the Canadian government has finally acknowledged its role in this genocide.

An account of doxastic morality that holds people responsible and morally blameworthy for the predictable consequences of our limited epistemic opportunities might be perverse. But, these wrongs at the level of the believer must be balanced against the fact that we must also do justice to this ongoing wrong that occurs when history is erased or forgotten. The wrong to First Nation, Inuit and Métis children is not just a wrong in how the Canadian government acted. If we do not accept responsibility and blame for our beliefs that are the result of forgetting or miseducation, we continue to

17 Gardiner (2018) notes this point as a challenge to any account of moral encroachment. She says, "[m]oral encroachment risks making epistemic justification contingent on myriad complex social factors that are intuitively irrelevant to epistemic justification." But here's the rub, beliefs are central to our social relationships with one another, and if we understand radical moral encroachment as a way of making good on the demand to stay woke, then the myriad of complex social factors are features of our epistemic environment that we ought be attending it. We are complex social creatures in a world shaped by complex social factors, it does not strike me as odd that epistemic justification would similarly be shaped by complex social factors given that every other part of life is. 
contribute to a terrifying epistemological reality for the First Nation, Inuit and Métis peoples: we devalue their lives and experiences (see also Dotson 2018).

Third, if one will fail to be justified in virtue of failing to appreciate the burden and risks that they impose on another, then almost all beliefs about other people-especially any belief about a person on the basis of their race or another protected class-are going to be high stakes. This seems overly demanding because it requires moral agents to be fairly sophisticated in recognizing when they should occupy this kind of moral standpoint. As a result, if this level of sophistication is beyond the reach of most, then most (maybe all) of our beliefs about individuals from non-dominantly situated groups are unjustified. After all, it is not clear whether most people would ever find themselves in a position to meet such a requirement.

My response should not be surprising. Morality is demanding. Moral encroachment brings moral considerations to bear on our epistemic practices. So, moral encroachment is similarly demanding. Recall that if we understand moral encroachment as a systematic treatment of the imperative to stay woke, staying woke is demanding. On does not simply wake up and stay woke. Rather, it is something that one has to work at everyday. Morality is much the same. There are moral costs associated with believing that should drive us to be more cautious. Given the picture we've been working with, we can see how the moral demands we place on one another extend beyond simply how we expect others to treat us, but also what others believe of us. All that moral encroachment requires is a certain level of epistemic humility when it comes to beliefs about others.

As Pamela Hieronymi $(2006,2008)$ has similarly noted, we are assessable for our epistemic characters. To practice the virtue of wokeness is to exercise a kind of indirect long-term control over how we engage in inquiry, what sources we attend to, when we stop inquiry and when we extend it, what evidence we look for and how we evaluate it, etc. Just as we are responsible and can be held accountable for the development of our moral character, I suggest that there is an epistemic virtue of wokeness that we are responsible and can be held accountable for, and that bears on the development of our epistemic character. It will be hard to sustain and develop this epistemic virtue, but it's not easy being a good person 


\section{WORKS CITED}

Basu, R. Forthcoming. The Wrongs of Racist Beliefs. Philosophical Studies.

Basu, R. 2019. What We Epistemically Owe To Each Other. Philosophical Studies 176(4).

Basu, R. and Schroeder, M. 2019. Doxastic Wronging. In Brian Kim \& Matthew McGrath (eds.), Pragmatic Encroachment in Epistemology, Routledge. pp. 181-205.

Begby, E. 2018. Doxastic morality: A moderately skeptical perspective. Philosophical Topics 46(1).

Bolinger, R. 2018. The rational impermissibility of accepting (some) racial generalizations. Synthese.

Brown, J. 2013. Impurism, Practical Reasoning, and the Threshold Problem. Nô̂s 47(1): 179-192.

Buchak, L. 2014. Belief, credence, and norms. Philosophical Studies, 169(2):285-311.

Code, L. 1987. Epistemic Responsibility. University Press of New England.

Conee, E. and Feldman, R. 2004. Evidentialism. Oxford University Press.

Dickey, B. 2017. Pit Bull: The Battle over an American Icon. Vintage.

Dotson, K. 2018. Accumulating epistemic power: A problem with epistemology. Philosophical Topics 46(1).

Douglas, H. 2009. Science, Policy, and the Value-Free Ideal. University of Pittsburgh Press.

Fantl, J. and McGrath, M. 2002, Evidence, pragmatics, and justification. The Philosophical Review, 111(1):67-94.

Fantl, J. and McGrath, M. 2009. Knowledge in an Uncertain World. Oxford University Press.

Fritz, J. 2018. From pragmatic encroachment to moral encroachment. Pacific Philosophical Quarterly.

Fritz, J. (in preparation). "Moral Encroachment and Reasons of the Wrong Kind.”

Gardiner, G. 2018. Evidentialism and Moral Encroachment. In McCain Kevin (ed.), Believing in Accordance with the Evidence.

Gendler, T. S. 2011. On the epistemic costs of implicit bias. Philosophical Studies, 156:3363.

Hieronymi. P. 2006. Controlling Attitudes. Pacific Philosophical Quarterly 87(1):45-74. 
Hieronymi, P. 2008. Responsibility for Believing. Synthese 161(3):357-373.

Kukla, R. 2015. Delimiting the proper scope of epistemology. Philosophical Perspectives 29:202-216.

Longino, H. E. 1987. Can There By A Feminist Science? Hypatia 2(3):51-64.

Moss, S. 2018a. Probabilistic Knowledge. Oxford University Press.

Moss, S. 2018b. Moral Encroachment, Proceedings of the Aristotelian Society 118(2): 177-205.

Munton, J. 2019. Beyond Accuracy: Epistemic Flaws with Statistical Generalizations. Philosophical Issues.

Pace, M. 2011. The epistemic value of moral considerations: Justification, moral encroachment, and James' 'Will to believe'. Noûs 45(2):239-268.

Paul, S. and Morton, J. 2018a. Believing in others. Philosophical Topics 46(1).

Paul, S. and Morton, K. 2018b. Grit. Ethics 129(2):175-203.

Ross, J. and Schroeder, M. 2012. Belief, credence, and pragmatic encroachment. Philosophy and Phenomenological Research.

Rudner, R. 1953. The scientist qua scientist makes value judgments. Philosophy of Science 20(1):1-6.

Schauer, F. F. 2006. Profiles, probabilities, and stereotypes. Harvard University Press.

Schroeder, M. 2018. When beliefs wrong. Philosophical Topics 46(1).

Stanley, J. 2005. Knowledge and Practical Interests. Oxford University Press.

Worsnip, A. 2015. Two kinds of stakes. Pacific Philosophical Quarterly 96:307-324.

Worsnip, A. Forthcoming. Can Pragmatists Be Moderate? Philosophy and Phenomenological Research. 